\title{
Resenha
}

\section{As muitas formas de pensar o cuidado em nossa sociedade}

\author{
TAMANINI, Marlene et al. O Cuidado em Cena: Desafios políticos, teóricos e \\ práticas. v. 1. Florianópolis: UDESC, 2018. 380 p. v. 1. ISBN 978-858302-141-1.
}

Enquanto uma perspectiva teórico-epistemológica profundamente inserida na área dos estudos de gênero, as discussões sobre os aspectos sociais do cuidado podem envolver as esferas econômicas, sociológicas, antropológicas, históricas, culturais, jurídicas, psicológicas, afetivas, biográficas e políticas. Proporcionam, assim, uma observação mais atenta das práticas e atitudes ligadas à manutenção da vida e do bem-estar diante da percepção da vulnerabilidade e da interdependência como condições humanas. Trata-se de uma proposta investigativa que evidencia contextos e relações sociais diversas. Os estudos sobre o cuidar propõem reflexões críticas sobre os arranjos da produção e reprodução na formação de imaginários sociais sobre homens provedores da esfera pública, chefes de família e autossuficientes - e mulheres - maternais e cuidadoras por abnegação, ligadas à dependência e ao âmbito doméstico. Ao mesmo tempo, leva em conta importantes discussões sobre desigualdades de raça, classe e gênero na distribuição e reconhecimento das atividades voltadas a sanar necessidades físicas, emocionais e materiais experimentadas por todos e todas ao longo da vida. Por sua potência política e analítica, esse ramo de estudos tem ganhado espaço no contexto acadêmico nacional ${ }^{1}$.

Dessa forma, a publicação de O Cuidado em cena: Desafios políticos, teóricos e práticos (2018) manifesta a amplitude temática e interdisciplinar abarcada

\footnotetext{
${ }^{1} \mathrm{O}$ reconhecimento da potência analítica dos estudos do cuidado é refletido em sua presença em eventos e publicações acadêmicas no Brasil - principalmente na área dos estudos de gênero. $\mathrm{O}$ encontro interdisciplinar Fazendo Gênero, organizado pela Universidade Federal de Santa Catarina, conta com simpósios temáticos sobre esse objeto desde sua décima edição, em 2013; o Seminário Nacional Sociologia \& Política, organizado pela Universidade Federal do Paraná, traz grupos de trabalho sobre o tema desde sua sexta edição, em 2015; o Simpósio Gênero e Políticas Públicas, organizado pela Universidade Estadual de Londrina, também dedica espaços à discussão do tema desde sua quarta edição, em 2016. Também é importante lembrar a construção de livros como Cuidado e Cuidadoras (2012), por Helena Hirata e Nadya Guimarães, e de volumes como o Dossiê Gênero e Cuidado, por Hirata e Guita Debet, dentro dos Cadernos Pagu, em 2016.
} 
pelas possibilidades surgidas da noção de cuidado. Trazendo essa perspectiva ao centro do palco, concedendo-lhe protagonismo analítico e explorando os mais diversos cenários em que o cuidar pode servir como lente de análise para a realidade contemporânea, esse livro se preocupa com as pungentes questões trazidas pela prática da pesquisa realizada em seus variados contextos empíricos. Organizado por Marlene Tamanini, Francisco G. Herdemann, Eliana Portes Vargas e Sandro Marcos Castro de Araújo, o volume conta com 12 capítulos pertencentes a múltiplos âmbitos disciplinares - da Sociologia à Literatura, passando pelo Direto, História e pela Saúde Pública -, apresentando um variado escopo teórico-metodológico.

O texto escrito por Marlene Tamanini abre o rol de capítulos e, por isso, se dedica a apresentar uma proposta epistemológica para alicercear a área dos estudos do cuidado como espaço de potência reflexiva e de articulação heurística para a produção de conhecimento capaz de conceber mudanças sociais. Para a autora, o âmbito das investigações sobre o tema surge como consequência dos debates feministas e seus desenvolvimentos dentro dos estudos de gênero. Dessa forma, a análise se inicia recuperando as discussões sobre a divisão sexual do trabalho, organizadas por pesquisadoras do feminismo entre 1960 e 1970, a fim de demonstrar a atenção voltada ao tema já nas discussões marcadas por uma revisão da perspectiva marxista a respeito das teorizações sobre a potência explicativa da noção de patriarcado. Mais à frente, Tamanini apresenta a discussão seminal proposta por Carol Gilligan em Uma voz diferente (originalmente publicado em 1982) e a insere nas discussões sobre a importância da diferença como escopo de estudos sobre a experiência das mulheres. Isto é, possibilitando novas formas de pensar ética e desenvolvimento moral sob uma perspectiva que leve em conta as questões de gênero que constroem nossas subjetividades. Partindo daí, o texto acompanha as consequências e ramificações do debate a respeito da importância do cuidado para pensar politicamente sobre identidades, práticas e disposições. A autora lembra, por exemplo, das reverberações maternalistas em busca de uma ética feminina e as críticas organizadas nos anos 1990, pautadas pela necessidade de uma discussão que centralizasse o cuidado como eixo para pensar a construção de uma sociedade democrática; rememora também as importantes repercussões desse debate no contexto francês, em que grande atenção foi dedicada às discussões sobre vulnerabilidade e dependência. Promovendo uma riquíssima recuperação das temporalidades e potencialidades da discussão, Tamanini enfatiza, por fim, a importância da multiplicidade temática e epistêmica do cuidado (demonstrada nos capítulo 
que seguem) em sua atenção aos diversos contextos empíricos aos quais se relaciona.

No capítulo seguinte, por sua vez, o cuidado é pensado desde a construção dos papéis de gênero e seus complexos desenvolvimentos ao longo da história do associativismo filantrópico feminino dos séculos XIX e XX. Acompanhando as trajetórias biográficas que marcaram a fundação da Associação de Damas de Assistência à Maternidade e à Infância em Curitiba, Ana Paula V. Martins remonta um contexto latino-americano de engajamento na proteção e assistência materno-infantil. Esse resulta do chamado médico e clerical para que as representantes das famílias tradicionais cumprissem seu dever moral de ajuda aos pobres com a habilidade maternal e bondosa que lhes foi atribuída pelo contexto discursivo ocidental moderno. Ao explorar o envolvimento das mulheres da elite na atividade caritativa, a autora propõe a potente ideia de uma dupla operação ideológica, na qual a participação dessas senhoras abastadas significava, ao mesmo tempo, um reforço essencialista das hierarquias de gênero e a possibilidade de mobilidade para além do âmbito privado através da participação beneficente na esfera pública. Assim, a autoridade moral feminina, ainda que não fosse ameaçadora à ordem social e de gênero, proporcionou também oportunidades de ação e conquista de novos espaços para as mães e esposas das ilustres famílias da época.

Escrito por Claudia Pedone, o terceiro capítulo apresenta um exemplo importante para a análise dos cruzamentos entre concepções do cuidado e a intervenção estatal na organização de famílias em situações de vulnerabilidade social. Refletindo sobre a combinação entre o agravamento da crise equatoriana e o aumento pela demanda de mão de obra feminina dentro do contexto europeu (sobretudo na Itália) dos anos 2000, a autora lança um importante olhar para as consequências de um cenário migratório em que as mulheres surgem como eixo central para a configuração transnacional das famílias e de sua manutenção prática e afetiva. Muitos são os desafios enfrentados pelas famílias vindas do Equador para a sobrevivência no contexto italiano, por exemplo: são diversos os relatos de conflitos entre pais, dificuldades geracionais, violências de gênero, precariedade econômica e, principalmente, riscos de separação entre crianças e familiares. Esse último elemento assume grande importância na investigação. O estudo mostra que, interpeladas pelo estigma da dependência, pela xenofobia e pela suposição de incapacidade moral de exercer o papel da "boa mãe", muitas das migrantes equatorianas têm de travar incessantes batalhas jurídicas e construir estratégias em seus cotidianos para lutar por direitos e manter suas famílias unidas - o que aponta 
para a urgência da necessidade de investigações sobre os dilemas da maternidade transpassada pelos contextos migratórios contemporâneos.

Atestando a amplitude dos temas a serem contemplados pelo intuito interdisciplinar com ao qual o livro se propõe, o próximo capítulo se debruça sobre as relações de sociabilidade transpassadas por raça e classe dentro do espaço doméstico burguês, relatado nas crônicas de Clarice Lispector. Em um estudo das maneiras pelas quais a autora retrata sua relação com suas exempregadas domésticas, Sonia Roncador analisa as formas como a obra de Lispector exprime conflitos sociais - atenuados, mas jamais resolvidos - que permeiam o cotidiano descrito em seus textos. Uma leitura minuciosa revela o convívio da escritora recifense com as subjetividades precarizadas que marcavam seu dia a dia, bem como suas consequências éticas. Essas variam entre a adoção autentificante de uma ética do cuidado maternal atenta às mazelas sociais brasileiras e uma culpa de classe, reveladora de uma disposição para perceber a desigualdade social que não se converte em ação efetiva sobre ela. Como cronista do Brasil da década de 1970, Lispector representa a figura perplexa do escritor que pouco se vê capaz de mudar o mundo e que pouco faz para revisar os estereótipos produtores de estigmas e injustiças sobre trabalhadoras domésticas no país.

Das Letras à Sociologia, o estudo de Thays A. Monticelli projeta outra perspectiva sobre as relações de cuidado e poder em torno do trabalho doméstico remunerado. Propõe uma análise das maneiras pelas quais "patroas" das classes médias e altas compreendem a transferência das atividades do cuidar para empregadas contratadas. Investigando a intersecção entre um quadro estrutural da divisão sexual do trabalho, a hierarquia das valorizações das atividades nos âmbitos público e privado, o agenciamento de desejos e as negociações subjetivas que marcam a transferência das responsabilidades pela limpeza, a autora mostra que os cuidados com o lar se tornam fonte de infelicidade para essas mulheres abastadas. Contudo, ligadas à função de gerenciadora dos cuidados da casa, ocupam um ambíguo lugar que as impele a exercer poder sobre mulheres pobres e negras. Esse poder se pronuncia em tons servilistas, através dos pormenores da "cultura doméstica" que, nas minúcias da higiene da casa, pauta os parâmetros para o impedimento de uma discussão democrática sobre as formas e reconhecimentos do cuidar em nossa sociedade.

A necessidade de construção de uma democracia do cuidado compõe o plano de fundo para o sexto capítulo do livro, escrito por Sandro M. C. de Araújo. Examinando as invisibilizações e essencializações que marcam o 
trabalho remunerado das cuidadoras de idosos portadores da síndrome Alzheimer, o autor reflete sobre motivações, negociações, cargas psicológicas e físicas que envolvem as atividades - ainda ignoradas pelo Estado brasileiro às quais essas mulheres se dedicam de forma remunerada. A constatação das vicissitudes que envolvem o trabalho de acompanhar pessoas em situação de envelhecimento ganha tons cada vez mais graves à medida que a tendência ao aumento da expectativa de vida no Brasil não é acompanhada por uma discussão séria e comprometida a respeito do papel do Estado na provisão de assistência para a população. $\mathrm{O}$ resultado de um debate ainda marcado pela feminilização naturalizante é, como mostra Araújo, o desamparo da população portadora de doenças degenerativas e, principalmente, a precarização das condições sob as quais operam as trabalhadoras da área.

Explorando de maneira diferente a relação entre cultura, cuidado e política, Marcela K. Brecailo propõe, a seguir, um interessante olhar às experiências de cuidar de crianças partilhadas por mulheres. Em uma análise fortemente influenciada pela obra de Flávia Biroli, a autora percorre uma miríade de relatos individuais que a auxiliam a entender as relações sociais ligadas às diferentes práticas da maternidade e da maternagem. $\mathrm{O}$ aleitamento materno, por exemplo, ganha importância fulcral no entendimento dos embates entre conhecimentos chancelados pelo Estado e vivências pautadas pelo saber popular. Brecailo investiga as estratégias que marcam a responsabilidade de mulheres que buscam ajuda na assistência de seus filhos e têm de lidar com os direcionamentos fornecidos pelas Unidades de Saúde e por suas familiares. Essa tensão se deve, em sua maior parte, por conta da dimensão estrutural que fixa o cuidar dentro do ramo de atividades essencialmente femininas. Assim, a atenção dedicada à criança surge como trabalho ainda pouco reconhecido no âmbito do privado - em função de uma valorização das atividades da esfera pública e masculina como única instância propriamente "produtiva". Tendo em vista a acentuada indisponibilidade dos homens em assumirem a partilha das atividades domésticas ou do cuidado das crianças fato há muito tempo estabelecido na área dos estudos feministas e de gênero , resta a essas mães o apoio em redes de solidariedade formadas por outras mulheres. Brecailo é categórica ao afirmar que cuidar de crianças é uma função social e deve ser encarada dessa forma pela ação estatal que, ignorando o tema, reforça o ciclo de não reconhecimento e a desvalorização do cuidado.

O capítulo seguinte explora, na experiência de catadoras de lixo da região metropolitana de Curitiba, os desafios que perpassam o cotidiano das mulheres que chegam à catação como resultado de um cenário marcado pela pobreza e 
pelas assimetrias de gênero em nossa sociedade. No texto, Daniela Kuhn e Gilson Queluz partem de uma perspectiva crítica ao capitalismo como modo de produção dentro do qual a forma como negligenciamos a importância da sustentabilidade não se separa da forma como despercebemos os corpos das trabalhadoras responsáveis por lidar com o lixo. Projetando uma união entre influências marxistas e a filosofia da abjeção de Judith Butler, os/as autores/as categorizam as catadoras como lupemproletariado que habita um espaço de abjeção - ilegível pelo Estado e pela sociedade civil. Trata-se de uma população de mulheres em situações economicamente vulneráveis que vêm nessa ocupação uma oportunidade para a sobrevivência. Em sua informalidade - que tem, como lado sombrio, a marca da desregulação e ausência de direitos - essa se torna uma das poucas saídas para o sustento da família dessas trabalhadoras. Como demonstram Kuhn e Queluz, abandonadas pela ação estatal e fruto da situação de pobreza, as catadoras têm enfrentado condições precárias que as igualam, aos olhos da sociedade, ao objeto com o qual trabalham: sentem-se parte do lixo.

O nono capítulo, escrito por Maria Izabel Machado, explora uma ramificação diferente dentro do amplo âmbito dos estudos do cuidado. Analisando as narrativas de mulheres que compõem grupos de trocas direta (produto por produto) em Curitiba e região metropolitana, a autora investiga as possibilidades do cuidado de si e de outros como forma de observar agência no cotidiano das participantes. Apropriando-se do referencial teórico foucaultiano, Machado explora as maneiras pelas quais a presença nesse coletivo organizado em torno de princípios da economia solidária existe através de tecnologias do eu. $\mathrm{O}$ ato de narrar-se, que transpassa as sociabilidades do clube de trocas, representa, para a autora, um aprendizado para o cultivo da própria subjetividade. À medida que se realiza em grupo, esse processo cria laços de solidariedade que apoiam mulheres em tempos de necessidades financeiras e crises emocionais. Ali se constrói um espaço de sociabilidade que lhes acolhe e oferece conforto para além das demandas de seus ambientes domésticos. Em um quadro de precarização e violências de gênero, o clube de trocas se mostra como um ambiente de empoderamento para suas participantes, em que podem olhar mais profundamente para suas vidas ao mesmo tempo em que amparam suas colegas.

A seção seguinte, inserida profundamente no campo da Saúde Pública, procura descrever as práticas de cuidado em torno dos tratamentos de tuberculose na favela da Rocinha, na cidade do Rio de Janeiro. O início do texto, pautado pela apresentação do Tratamento Diretamente Observado (TDO) 
como tecnologia de verificação presencial do uso do remédio por profissionais de saúde e familiares, nos leva a pensar que se trataria de uma análise exemplar dos mecanismos de controle social por parte do Estado. Contudo, o trabalho de Raquel B. A. Araújo, Marly M. da Cruz e Eliane P. Vargas explora uma diferente forma de pensar o encontro entre indivíduos e ação estatal. Assim, percorrem os caminhos da tentativa de construção de um tratamento humanizado e integralizado - marcado por negociações, tensões e afetos na construção de um vínculo entre usuário do tratamento e agente de saúde que o promove. Considerando um amplo espectro empírico, nota-se um largo conjunto de componentes que influenciam na efetivação do acompanhamento médico - esses variam desde a violência do ambiente no qual vivem os pacientes até as diversas especificidades de seus cotidianos. Trata-se de um esforço para observar o árduo trabalho de personalização do atendimento individual no combate a uma doença já, de saída, acentuada pelas mazelas da desigualdade social em nosso país.

Com um retorno ao tema da imigração, sem abandonar a abordagem crítica da relação entre Estado e populações desprivilegiadas, Cláudia Medeiros de Castro reflete sobre os cuidados obstétricos oferecidos para mulheres que vieram de outros países e hoje vivem na cidade de São Paulo. Mesmo compondo o capítulo mais curto do livro, a análise se mostra bastante contundente em explorar uma invisibilidade da condição feminina imigrante nas normativas da Política Nacional de Atenção Integral à Saúde da Mulher. $\mathrm{Na}$ prática, esse quadro resulta em desencontros que permeiam a relação dessas mães com o Sistema Único de Saúde - marcada por barreiras de comunicação, ignorância diante de diferenças culturais da maternidade e desconsideração das condições de trabalho de imigrantes pobres no Brasil. No texto, a autora clama por uma ampliação intercultural dos modelos para integração entre ação estatal e a população a qual deve garantir direitos básicos.

O último capítulo do livro traz talvez o maior desafio para os limites abarcadores do conceito de cuidado. Nicolle Feller promove uma inovadora discussão sobre aspectos morais e jurídicos a respeito da manifestação antecipada de pacientes no que tange sua própria morte. Ainda que o cuidar seja uma atividade comumente ligada à manutenção da vida e do bem-estar, como pensá-lo quando não há possibilidade de viver com dignidade? Como encarar o desejo previamente estabelecido de abrir mão do direito à vida quando esta já não puder ser vivida dignamente - isto é, sem que seja marcada por enormes custos físicos, psicológicos e emocionais para o sujeito em questão e aqueles que o cercam? Que tipo de responsabilidade pode ser imputada ao 
profissional da saúde que concorde em participar do processo de morrer de maneira assistida? Operando uma discussão que enfrenta as lacunas legislativas entre o Direito e a Bioética, a autora explora essas questões enquanto advoga pela necessidade de uma ação médica dialógica que respeite a experiência e o direito de escolha do indivíduo. Ainda que destoe das outras seções do compêndio, não se reportando aos estudos de gênero e seguindo um método de investigação mais próximo das ciências jurídicas, a proposta de Feller apresenta importantes debates para expandir as possibilidades de pensar o cuidado em relação às formas de morrer e viver dignamente.

Em suma, trata-se de um livro marcado por um debate amplo e variado, sem que, com isso, se torne disperso em suas discussões. Como parte de um aporte epistemológico amplo, os estudos acima convergem na afirmação da importância do cuidado para a reimaginação crítica e politicamente engajada das relações interpessoais e da organização de nossa sociedade. Transpassados por desafios comuns que circulam em torno da invisibilização do cuidar em nossas representações sociais e âmbitos de debate público e institucional, os diferentes capítulos retornam ao eixo das assimetrias que marcam a divisão sexual do trabalho, a construção das subjetividades gendrificadas e as negociações da intimidade que permeiam os múltiplos cenários através dos quais esse tipo de atividade deve ser retratado como questão social relevante para pensar a contemporaneidade em suas facetas diversas.

Colocar o cuidado "em cena" é fazer dele um dos protagonistas de nossas interpretações do mundo - em resposta ao longo tempo em que permaneceu na penumbra dos bastidores. Sob o holofote, seu caráter multifacetado é também a medida de sua potência investigativa. Assim, como parte de um debate que tem crescido e se consolidado na realidade acadêmica brasileira, $O$ Cuidado em Cena é uma publicação proveitosa para aqueles e aquelas que desejam conhecer mais sobre o tema, suas diversas ramificações e possibilidades dentro de diferentes áreas do conhecimento.

Henrique da Costa Valério Quagliato²

\section{Recebido em}

março de 2020

\section{Aprovado em}

setembro de 2020

2 Doutorando pelo Programa de Pós-Graduação em Sociologia pela UFPR. E-mail: henriquequagliato95@gmail.com. 